Vol. 5. No.1, April, 2017: 63-69, ISSN (cet): 2355-1755 | ISSN (online): 2579-6437

\title{
PRODUK PEMBIAYAAN SOSIAL PADA PERBANKAN SYARIAH DI INDONESIA
}

\author{
Falikhatun ${ }^{1}$, Sri Iswati², dan Mohammad Saleh ${ }^{3}$ \\ ${ }^{I}$ Afiliasi: Business and Economic Faculty and Peer Group of Center for Islamic Economic \\ Studies Universitas Sebelas Maret, Surakarta, Indonesia. Email: falie_008@yahoo.com \\ ${ }^{2}$ Afiliasi: ${ }^{2}$ Business and Economic Faculty, Universitas Airlangga, Surabaya, Indonesia. Email: \\ iswati.feua@gmail.com \\ ${ }^{3}$ Afiliasi: Business and Economic Faculty, Universitas Jember, Indonesia. Email: \\ Fe.m.saleh@gmail.com
}

ABSTRAK. Penelitian ini bertujuan untuk menganalisis secara mendalam mengenai produk pembiayaan sosial pada perbankan syariah di Indonesia. Paradigma yang digunakan dalam penelitian ini adalah paradigma interpretif dengan pendekatan fenomenologi. Pendekatan ini digunakan untuk menggali informasi yang terkait dengan pengalaman Muqridh (orang yang berpiutang) dalam implementasi produk pembiayaan sosial. Pengumpulan data dilakukan dengan wawancara mendalam, observasi dan dokumentasi, sedangkan analisis yang digunakan adalah Analisis Fenomenologi Interpretatif. Hasil analisis menyimpulkan bahwa menurut pengalaman Muqridh, obyek produk pembiayaan sosial pada perbankan syariah di Indonesia meliputi Uang Muka Gaji (UMG), Rahn Emas dan Hawalah

Kata kunci: Hawalah, Rahn Emas, Uang Muka Gaji

ABSTRACT. The study aims to analyze in depth about social financing products on Islamic banking in Indonesia. The paradigm that is used in this research is interpretive paradigm approach to Phenomenology. This approach is used to dig up the information associated with the experience of Muqridh in the implementation of social financing products. Data collection is done with the interview, observation and documentation, while analysis is the analysis of Interpretive Phenomenology. The results of the analysis concluded that according to the experience of the Muqridh, the object of social financing products on Islamic banking in Indonesia include an advance salary, the gold Rahn and the Hawalah

Keywords: Hawalah, Gold Rahn Emas, Advance salary

\section{PENDAHULUAN}

Produk-produk pembiayaan syariah digolongkan ke dalam lima kategori berdasarkan tujuan penggunaannya yaitu: (a) pembiayaan dengan prinsip buyu' (Murabahah, Salam, dan Istisna'); (b) pembiayaan dengan prinsip sewa (Ijarah); (c) pembiayaan dengan prinsip Syirkah (Musyarakah, Mudharabah, Muzara'ah, dan Musaqah); (d) fee based service atau jasa (Wakalah, Kafalah, Hawalah, Rahn); dan (e) produk sosial (Qardh dan Qardh al-Hasan) (Adnan dan Furywardhana, 2006: 156). 
Implementasi produk sosial didasarkan pada fatwa MUI No. 19/DSNMUI/IV/2001 tentang Qardh yang dananya bersumber dari bagian modal dan keuntungan yang disisihkan dari Lembaga Keuangan Syariah (LKS), serta lembaga lain atau individu yang mempercayakan penyaluran infaqnya lewat LKS. Pada tahun 2011, MUI kembali mengeluarkan fatwa Qardh dengan No. 79/DSN-MUI/III/2011 yang sumber dananya berasal dari nasabah. Jika dibandingkan dengan fatwa MUI tahun 2001, fatwa MUI tahun 2011 ini dimungkinkan dapat menimbulkan kemadharatan yang lebih besar apabila terjadi piutang qardh yang tidak tertagih karena sumber dananya berasal dari nasabah.

Fenomena Qardh bisa dikaji dari berbagai perspektif, baik dari sisi sistem, maupun dari sisi pelakunya, yaitu Muqridh (orang/lembaga pemberi pinjaman) dan Muqtaridh (penerima pinjaman). Dari perspektif sistem, beberapa penelitian sebelumnya telah mengkaji pada mekanisme dan prosedur Qardh (Zaher and Hasan, 2001; Santoso, 2005; Abdullah and Rahman, 2007; Farooq, 2008; Mustafa and Ismailov, 2008; Ariffin and Adnan, 2009; Jalil, Md and Rahman, 2010; Onagun, 2011), baik dari sisi tujuan maupun penerima pinjaman. Selanjutnya dari perspektif metodologi, penelitian tentang Qardh lebih banyak menggunakan metoda studi kasus (Santoso, 2005)., survei (Zaher, at.al., 2001; Ariffin, et.al., 2009 dan Amin, 2010) dan studi literatur ( Asgary, 2007; Mirachor, et.al, 2007; Farooq, 2008; Farah, 2009; Jalil Md, at.al., 2010 dan Onagun, 2011).

Namun riset-riset sebelumnya lebih banyak mengekplorasi permasalahan Qardh pada tataran deskriptif, sehingga kurang mampu menangkap fenomena yang tersembunyi. Oleh karena itu penelitian ini mencoba untuk menginvestigasi lebih dalam dan lebih detail mengenai pengalaman Muqridh dalam implementasi Qardh pada perbankan syariah, sehingga pertanyaan penelitiannya adalah bagaimanakah pengalaman Muqridh dalam implementasi Qardh pada perbankan syariah?

\section{METODE PENELITIAN}

Jenis penelitian ini adalah penelitian kualitatif dengan menggunakan latar alamiah yang bertujuan menafsirkan fenomena yang terjadi dan dilakukan dengan jalan melibatkan berbagai metoda yang ada. Paradigma yang digunakan dalam penelitian ini adalah paradigma interpretif. Paradigma interpretive didasarkan pada keyakinan bahwa individu (manusia) merupakan mahluk yang secara sosial dan simbolik membentuk dan mempertahankan realita mereka sendiri (Berger and Luckmann, 1967; Morgan and Smircich, 1980) dalam Mulyana (2011). Pendekatan penelitian yang digunakan adalah fenomenologi. Pendekatan ini dirintis oleh Edmund Husserl (1859-1938) (Moran, 2000:1). Pendekatan fenomenologi berusaha mengungkapkan makna dari pengalaman seseorang. Makna tentang sesuatu yang dialami seseorang sangat tergantung bagaimana orang berhubungan dengan sesuatu (Edgar and Sedgwick, 1999:273). 
Jurnal Ekonomi dan Perbankan Syariah

Vol. 5. No.1, April 2017: 63-69, ISSN (cet): 2355-1755 | ISSN (online): 2579-6437

| 65

Penelitian dilakukan pada beberapa Bank Umum Syariah di Surakarta, yaitu PT Bank Muamalat Indonesia, PT Bank Syariah Mandiri, PT Bank Negara Indonesia Syariah dan Unit Usaha Syariah PT Bank Tabungan Negara. Metoda pengumpulan data dilakukan dengan wawancara mendalam, observasi dan dokumentasi. Analisis yang digunakan meliputi Analisis Fenomenologi Interpretatif (Interpretative Phenomenological Analysis). IPA bertujuan untuk mengeksplorasi secara rinci bagaimana seseorang memahami dirinya dan lingkungan di sekitarnya mengenai pengalaman mereka terhadap sesuatu. Sasaran utamanya adalah makna berbagai pengalaman, peristiwa, dan status yang dimiliki oleh partisipan.

IPA telah banyak digunakan dalam penelitian psikologi seperti Morgan and Arcelus (2009), Borkoles, et.al (2008), Jarman, Walsh and de Lacey (2005), Wilson and Sperlinger (2004), Clare (2003), Riggs and Coyle (2002), Smith (2008), Golsworthye and Coyle (1999), Flower, Smith, Sheeran and Beail (1997). Awalnya metoda ini hanya digunakan dalam bidang psikologi, namun sekarang sudah banyak digunakan pada bidangbidang yang lain (Igor and Smith, 2012:364). Adapun Analisis Fenemenologi Interpretatif mengacu pada Smith (2009: 79-107) dengan modifikasi.

\section{PEMBAHASAN}

Hasil Analisis Fenomenologi Interpretif menghasilkan beberapa temuan yang terkait dengan implementasi Qardh pada perbankan syariah di Indonesia antara lain Uang Muka Gaji (UMG), Rahn Emas dan Hawalah.

\subsection{UANG MUKA GAJI (UMG)}

Uang Muka Gaji, merupakan pinjaman tanpa agunan yang diberikan khusus kepada karyawan bank syariah sebagai salah satu peningkatan kesejahteraan karyawan. Dalam implementasinya pada perbankan syaraih, sebagian besar sumber dananya berasal dari Dana Pihak Ketiga Terutama Giro Wadiah yaddhamanah. Padahal. Seharusnya uang titipan dari para nasabah digunakan untuk aktifitas tijarah yang menghasilkan keuntungan, sehingga nasabah sebagai pemilik dana mendapatkan manfaat dalam bentuk bonus dan bagi hasil atas dana yang dititipkan dan diinvestasikan kepada bank syariah. Namun dengan Qardh yang hanya ditujukan untuk kesejahteraan karyawan, artinya kesempatan untuk meningkatkan jumlah pendapatan dari aktivitas tijarah semakin kecil, karena adanya alokasi dana yang digunakan untuk UMG. Akibatnya jumlah pendapatan yang seharusnya dinikmati oleh nasabah malah dinikmati oleh karyawan perbankan syariah. Di sini jelas ada kemungkinan ketidakadilan yang dilakukan oleh perbankan syariah kepada nasabah.

Selanjutnya apabila dilihat dari jangka waktu akad dengan minimal 3 tahun dan maksimal 5 tahun, artinya uang yang tertanam dalam pinjaman 
tersebut cukup lama dan tidak bisa digunakan untuk melakukan investasi yang lebih menguntungkan. Pada akhirnya kesempatan untuk meningkatkan pendapatan semakin kecil, akibatnya peluang untuk mendapatkan bonus bagi nasabah dengan jumlah yang lebih tinggi juga semakin kecil, apalagi kebijakan pemberian bonus sangat tidak mengikat. Terakhir dari sisi penentuan ujrah untuk UMG yang didasarkan pada prosentase juga sangat memungkinkan terjerumus kepada riba nasiah.

Praktik tersebut tentu saja tidak sesuai dengan Prinsip Amanah yang menyatakan bahwa amanah sebagai titipan yang menjadi tanggungan, bentuk kewajiban yang harus dibayar (Tasmara, 2002:95), dan amanah juga mengindikasikan eksisitensi kesadaran individu tentang perannya sebagai wakil Allah SWT dan memainkan peran sesuai dengan aturan dan normanorma Tuhan (Triyuwono, 2006:183). Ketika uang titipan nasabah yang merupakan amanah tidak digunakan sesuai dengan tujuannya, hal ini berarti perbankan syariah telah berlaku khianat kepada nasabahnya. Selanjutnya apabila dikaitkan dengan Teori Maslahah, Uang Muka Gaji juga tidak berkaitan dengan optimalisasi manfaat pembiayaan yang diakukan oleh perbankan syariah (karena hanya dinikmati oleh kelompok tertentu/karyawan bank), sehingga tidak berdampak langsung pada peningkatan kesejahteraan masyarakat secara luas.

\subsection{RAHN EMAS (GADAI)}

Dalam implementasi Qardh beragun Emas pada perbankan syariah, obyek yang bisa dijadikan Qardh beragun emas adalah logam mulia (perhiasan) dan emas bersertifikasi dari PT. ANTAM (Persero) Tbk. Padahal dalam Surat Edaran BI Nomor 14/7/DPbS tanggal 29 Februari 2012, yang bisa dijadikan agunan dalam Qardh beragun Emas hanya Emas bersertifikasi yang dikeluarkan oleh PT. ANTAM (Perseo) Tbk. Kemudian untuk jumlah pembiayaan dibandingkan dengan nilai agunan atau Financing to Value (FTV) sebesar $85 \%$ dari nilai taksasi untuk logam mulia, sedangkan untuk Emas bersertifikasi sebesar 90\% dari rata-rata harga jual emas 100 gram dan harga beli kembali (buyback) emas PT. ANTAM (Persero) Tbk., padahal dalam SE di atas FTV maksimal sebesar $80 \%$ dari rata-rata harga jual emas 100 gram dan harga beli kembali (buyback) emas PT. ANTAM (Persero) Tbk.

Apabila dirujukkan dengan Surat Edaran di atas, maka ada dua pelanggaran yang terjadi dalam implementasi Qardh beragun Emas pada perbankan syariah di Surakarta, yaitu: (1) jaminan Qardh beragun Emas seharusnya hanya Emas 24 karat bersertifikasi dari PT. ANTAM (Persero) Tbk., tetapi kenyataannya perhiasan emas juga diperbolehkan untuk dijadikan Rahn, dan (2) FTV yang seharusnya hanya $80 \%$ dari nilai rata-rata harga jual emas 100 gram dan harga beli kembali (buyback) emas, namun kenyataannya sebesar $85 \%$ dari nilai taksasi untuk logam mulia, dan untuk Emas bersertifikasi sebesar $90 \%$ dari rata-rata harga jual emas 100 gram dan harga beli kembali (buyback) emas PT. ANTAM (Persero) Tbk. Dengan demikian, sesuai dengan karakteristik Qardh beragun Emas, terutama karakteristik 
Jurnal Ekonomi dan Perbankan Syariah

Vol. 5. No.1, April 2017: 63-69, ISSN (cet): 2355-1755 | ISSN (online): 2579-6437

167

nomor 5, maka Bank Syariah atau UUS yang menjalankan produk Qardh Beragun Emas di wilayah Surakarta tidak sesuai dengan ketentuan yang diatur dalam SE BI Nomor 14/7/DPbS tanggal 29 Februari 2012 perihal Produk Qardh beragun Emas dan dapat dikenakan sanksi berupa penghentian produk tersebut.

\subsection{HAWALAH}

Praktik hawalah yang pada perbankan syariah menggunakan jenis hawalah muthlaqah, artinya hawalah yang terjadi di mana muhil adalah orang yang berutang, tetapi tidak berpiutang kepada muhal 'alaih. Selanjutnya hawalah yang diimplementasikan pada perbankan syariah di Surakarta ada dua macam yaitu hawalah bil ujroh dan hawalah dengan akad tijari misalanya hawalah bil murahabah, hawalah bil mudharabah dan hawalah bil musyarakah.

Apabila dilitik dari Fatwa DSN MUI Nomor 58/DSN-MUI/V/2007 tentang Hawalah bil Ujrah, maka implementasi akad hawalah yang sesuai dengan dengan fatwa tersebut adalah hawalah bil ujroh, sedangkan impelmentasi hawalah yang menggunakan akad lain seperti hawalah bil murahahah, hawalah bil mudharabah atau hawalah bil musyarakah tidak sesuai dengan syariah Islam, karena menggabungkan akad tabarru' dan akad tijari.

\section{SIMPULAN}

Hasil analisis data yang telah dilakukan menyimpulkan beberapa hal, yaitu: (1) Menurut pengalaman Muqridh dan Muqtaridh, Qardh pada perbankan syariah di Indonesia diimplementasikan dalam obyek Uang Muka Gaji (UMG), Rahn Emas, dan Hawalah, (2) Sumber dana Produk Pembiayaan Sosial berasal dari Simpanan dan Dana Syirkah Temporer.

Saran penelitian ini terutama diajukan bagi (1) Dewan Syariah Nasional (DSN) MUI diharapkan menerbitkan buletin yang berkaitan dengan operasionalisasi Fatwa yang telah dikeluarkan, khususnya Qardh agar memudahkan pengelola perbankan syariah dalam mengimplementasikan Fatwa-fatwa tersebut, dan (2) peneliti berikutnya dapat mengembangkan penelitian yang berkaitan dengan kelembagaan Perbankan Syariah, produkproduk perbankan syariah, pengawasan perbankan syariah dan Akuntansi Perbankan Syariah.

\section{DAFTAR PUSTAKA}

Adnan, M. A., \& Furywardhana, F. (2006). Evaluasi Non Performing Loan (NPL) Pinjaman Qardhul Hasan (Studi Kasus di BNI Syariah Cabang Yogyakarta). Jurnal Akuntansi dan Auditing Indonesia, 10(2). 
Amin, H., Ghazali, M. F., \& Supinah, R. (2010). Determinants of Qardhul Hassan Financing Acceptance among Malaysian Bank Customers: An Empirical Analysis. International Journal of Business and Society, $11(1), 1$.

Ariffin, N. M., \& Adnan, M. A. (2009). The perceptions of Islamic Bankers on Qardhul Hasan in Malaysian Islamic Banks.. www.googlescholar.com

Asgary, Ali. (2007). Informal Microfinance Institutions: Case of Qard hasan Funds in Iran: in Non-bank Financial Institutions: Islamic Alternatives. Islamic Research and Training Institute, Jeddah, Saudi Arabia.

Bank Indonesia. 2012. Surat Edaran Nomor 14/7/DPbS terntang Produk qardh beragun Emas bagi Bank Syariah dan Unit Usaha Syariah, tanggal 29 Februari 2012.

Borkoles, E., Nicholls, A. R., Bell, K., Butterly, R., \& Polman, R. C. (2008). The lived experiences of people diagnosed with multiple sclerosis in relation to exercise. Psychology and Health, 23(4), 427-441.

Clare, L. (2003). Managing threats to self: awareness in early stage Alzheimer's disease. Social science \& medicine, 57(6), 1017-1029.

Dewan Syariah Nasional-Majeleis Ulama Indonesia. Fatwa DSN No. 12/DSN-MUI/IV/2000, tentang Hawalah. www.mui.or.id
--------, Fatwa DSN No. 19/DSN-MUI/IV/2001, tentang al-Qardh. www.mui.or.id
tentang Rahn. www.mui.or.id

$$
\text { Fatwa DSN No. 25/DSN-MUI/IV/2002, }
$$ , Fatwa DSN No. 26/DSN-MUI/IV/2002, tentang Rahn Emas. www.mui.or.id

tentang Pengalihan Hutang. www.mui.or.id

tentang Hawalah bil Ujrah. www.mui.or.id

Farah, Abdul Fatah M. (2009). Charitable Investment Banking Model: An Islamic Perspective. Conference of Islamic Perspective on Management and Finance, 2 - 3 Juli 2009.

Farooq, Mohammad Omar. (2008). Qardh al-Hasana, Wadiah/Amanah and Bank Deposit: Apllication and Misapplication of Some Concepts in Islamic Banking. Harvard Islamic Forum, April 19 - 20, 2008. www.srrn-1d1418202-1,pdf.

Flowers, P., Smith, J. A., Sheeran, P., \& Beail, N. (1997). Health and romance: Understanding unprotected sex in relationships between gay men. British Journal of Health Psychology, 2(1), 73-86.

Golsworthy, R., \& Coyle, A. (1999). Spiritual beliefs and the search for meaning among older adults following partner loss. Mortality, 4(1), $21-40$. 
Jurnal Ekonomi dan Perbankan Syariah

Vol. 5. No.1, April 2017: 63-69, ISSN (cet): 2355-1755 | ISSN (online): 2579-6437

| 69

Pietkiewicz, I., \& Smith, J. A. (2014). A practical guide to using interpretative phenomenological analysis in qualitative research psychology. Psychological Journal, 20(1), 7-14.

Ismail, Abdul Ghafar. (2010). Money, Islamic Banks and the Real Economy. Cengage Learning Asia Pte Ltd.

Jalil, Abdul. Md. (2010). Financial Transaction in Islamic Banking are Viable Alternatives to the Conventional Banking Transactions. http;//www.ijbssnet.com.journals/vol.1_No._3_December_2010/22/ $p d f$.

Jarman, M., Walsh, S., \& De Lacey, G. (2005). Keeping safe, keeping connected: A qualitative study of HIV-positive women's experiences of partner relationships. Psychology \& Health, 20(4), 533-551.

Mirachor, Abbas and Iqbal, Zamir. (2007). Qardhul Hasan Microfinance. New Horizon, April-Juni 2007.

Moran, Dermont. (2000). Introduction to Phenomenology. Routledge, Taylor \& Francis Group, London and New York.

Mulyana, Deden. (2011). Landasan Filsafat Metode Penelitian Kualitatif. Paper disampaikan pada Seminar Nasional Metode Penelitian Kualitatif, tanggal 9 Juni 2011.

Mustafa, Z., \& Ismailov, N. (2008). Entrepreneurship and Microfinance-A tool for empowerment of poor-Case of Akhuwat, Pakistan. Mälardalens högskola.

Onagun, A. I., \& Ismail, A. (2011, March). Solvency of Takaful Fund: A Case of Subordinated Qard. In 2nd International Conference on Business and Economic Research (2nd ICBER 2011) Proceeding. Conference Master Resources.

Santoso, A. Y. (2005). Pelaksanaan Akad Pembiayaan Qardh pada Bank BRI Syariah Cabang Semarang (Doctoral dissertation, program Pascasarjana Universitas Diponegoro).

Smith, J. A., \& Osborn, M. (2008). Interpretative Phenomenological Analysis. In J. Smith, Qualitative Psychology: A Practical Guide to Research Methods. pp. 53-80. London: Sage.

Smith, Jonathan A., Flowers, Paul., and Larkin. Michael. (2009). Interpretative Phenomenological Analysis: Theory, Method and Research. Los Angeles, London, New Delhi, Singapore, Washington: Sage.

Tasmara, Toto. (2002). Membudayakan Etos Kerja Islami. Penerbit: Gema Insani Press, Jakarta.

Triyuwono, Iwan. (2006). Akuntansi Syariah: Perspektif, Metodologi dan Teori. Penerbit: Rajawali Press, Jakarta.

Zaher, T. S., \& Kabir Hassan, M. (2001). A comparative literature survey of Islamic finance and banking. Financial Markets, Institutions \& Instruments, 10(4), 155-199. 
70 | Falikhatun, Iswati \& Saleh: Produk Pembiayaan Sosial pada... 